\title{
SEQUENTIAL CAPITAL INVESTMENT DECISION MAKING UNDER EXTREME CASH FLOW SITUATIONS: EVIDENCE USING MONTE CARLO SIMULATION
}

\author{
Wenqing ZHANG ${ }^{1}$, Prasad PADMANABHAN ${ }^{2}$, Chia-Hsing HUANG ${ }^{3}$ \\ ${ }^{1}$ Labovitz School of Business and Economics, University of Minnesota Duluth, \\ 1318 Kirby Drive, Duluth, MN 55812-3029, United States \\ ${ }^{2}$ Greehey School of Business, St. Mary's University, One Camino Santa Maria, \\ San Antonio, Texas, United States \\ ${ }^{3}$ SolBridge International School of Business, 128 Uam-ro, Dong-gu, \\ Daejeon, Republic of Korea \\ E-mails: ${ }^{1}$ wqzhang@d.umn.edu; ${ }^{2}$ ppadmanabhan1@stmarytx.edu; \\ 3koreasing@solbridge.ac.kr (corresponding author)
}

Received 10 May 2014; accepted 6 April 2015

\begin{abstract}
Uncertainty influences a decision maker's choices when making sequential capital investment decisions. With the possibility of extremely negative cash inflows, firms may need to curtail operations significantly. Traditional Net Present Value analysis does not allow for efficient management of these problems. In addition, firm managers may behave irrationally by accepting negative Net Present Value projects in the short term. This paper presents a Monte Carlo simulation based model to provide policy insights on how to incorporate extreme cash flows and manager irrationality scenarios into the capital budgeting process. This paper presents evidence that firms with irrational managers and experiencing extremely negative cash flows may, under certain conditions, reap long term rewards associated with the acceptance of negative Net Present Value projects in the short term. These benefits are largest if cost ratios (discount rates) are small, or investment horizons are high. We argue that acceptance of short term negative Net Present Value projects implies the purchase of a long term real option which can generate positive long term cash flows under certain conditions.
\end{abstract}

Keywords: sequential capital investment, extreme values, Monte Carlo simulation, real options, uncertainty, net present value.

JEL Classification: G31, G32.

\section{Introduction}

In general, three important factors, namely, sunk cost, risk and the option to shutdown, influence corporate decision making regard capital investments. Investment cost outlays generally tend to be large and irreversible with low residual values once adopted. Project risk (defined by uncertainties in future revenues and costs over time) can impact acceptance decisions. 
However, the 1997 Asian financial crisis and the 2008 global subprime crisis have forced firms to consider that the unpleasant impact of major negative shocks ${ }^{1}$ (possibly occurring at the tail end of probability distributions), can make a profitable project turn sour and render traditional net present value (NPV) analysis less effective. Well established/experienced firms may be expected to handle such problems easily, but the 1980 Union Carbide tragedy suggests that even such firms are not immune to the resultant negative aftermath of a crisis.

Managers also invest in negative NPV projects because of overconfidence placed on their subjective estimates of cash flows and may continue to invest in short run negative NPV projects in the belief that project cash flows will become positive in the long run. Informational asymmetries related to project cash flows between the manager and those directly involved in the project can exacerbate such problems if managers underestimate the probability and/or the amount of loss if projects fail. Under extreme cash flow (ECF) conditions, the tendency to continue investments in negative NPV projects can increase firm losses because of possible simultaneous compounding of agency and information asymmetry problems. On the plus side, a manager's tendency to persist with short run negative NPV projects can provide long term gains for the firm. There is casual empirical evidence that firms can receive unexpected benefits by persisting with short term negative NPV projects $^{2}$.

However, there is no guarantee that a project profitable in the short term will always generate profits in the long term. Rational Union Carbide managers would have had little reason to terminate operations during the crisis faced by the Bhopal subsidiary of the firm in the 1980s. Nevertheless, in hindsight, the Bhopal tragedy indicates that the subsidiary should have been closed completely before the tragedy occurred. An aggressive manager may have irrationally terminated the positive NPV project in the short term, and these actions would have been the correct one, in light of subsequent events. Furthermore, the Exxon Valdez oil spill, the recent British Petroleum Gulf of Mexico related problems (to name a few) ${ }^{3}$ suggest that firms now face situations where good projects can go bad in a hurry. Yet, these firms did not curtail these projects, but instead dealt with it in a systematic way to the extent that we can now conclude that full recovery has taken place for most of these affected firms. The message here is that if managers take short-term risks (as an aggressive manager would), or face an extreme/ unexpected catastrophic loss situation, they have two choices. They can continue with the unprofitable project, or terminate it. These decisions can generate profits for the firm over the long term.

To date, and to the best of our knowledge, there have been little attempts in the academic literature to provide guidance for managers on how to handle extreme negative

\footnotetext{
${ }^{1}$ These situations can be viewed as extreme cash flow shocks to the firm.

${ }^{2}$ Or when they are forced to sell assets in a host country, for instance, under forced nationalizations. This evidence is documented later in the paper.

${ }^{3}$ More examples of firms facing catastrophic (or extreme) events can be found in Knight and Pretty (1996).
} 
cash flow uncertainty. Since the incidence of extreme crisis type situations has increased in recent times, firms may benefit from proactive management of such situations. In addition, given the paucity of academic papers addressing both types of extreme scenarios (ECFs and the presence of aggressive managers) simultaneously, we develop a simulation-based model that accommodates both scenarios within a traditional framework. Using this model, we attempt to provide simulation-based answers to the following questions: Does a firm benefit from continuing to invest in projects unprofitable in the short term? Should firms tolerate managers who are predisposed to assuming greater risks? Will their persistence with projects unprofitable in the short run pay off in the long run? Will the possibly of extreme cash flows influence these results?

\section{Literature review}

The literature is replete with examples of how uncertainty in future expected cash flows should be handled when making capital investments. The future uncertain stochastic outcome (the future cash flows) has been modeled as a single period valuation model (Sharpe 1964), a multi-period one (Rubinstein 1976), or as a model using option pricing theory (Black, Scholes 1973). Other developments that address some of the limitations of earlier models include the works of Merton et al. (1977), and Cox et al. (1979). Textbooks recommend the NPV, the adjusted NPV, or the real options methodologies, to handle investment uncertainty (Abel et al. 1996). Real option models have been suggested as a way to address investment decisions when there is demand uncertainty.

The real options model is more appropriate for evaluating firm investment decisions when uncertainty can be resolved within the investment horizon period, such as when firms face options to abandon, expand, or contract (Dixit 1989; Pindyck 1991; List, Haigh 2010; Denison et al. 2012; Sewalk, Dai 2014). Researchers have generally formulated real options models using three popular processes, namely, geometric Brownian motion, mean reversion process, and the lattice model. Whereas the geometric Brownian motion process provides closed form solutions when price uncertainties are present (Brennan, Schwartz 1985; Tsekrekos et al. 2012), they do not provide an equilibrium price process. Next, although the mean reversion process is better able to model uncertain cash flows and provide an equilibrium price process, the generated results underestimate volatility and discount rate biases (Lund 1993). Researchers have included an infrequent jump process to combat these biases (Dixit 1994; Hubbard 1994; Chang, Chen 2012). In addition, these models are better able to capture situations where large cash flow shocks are prevalent (for instance, those induced by pandemic financial crises and/or war). Finally, the lattice model is more appropriate when analytical solutions do not exist or when multiple integrations are needed to generate analytical solutions (Dai et al. 2013). For instance, the binomial lattice model developed by Cox et al. (1979) provides intuitive solutions if there is only one state variable. The three jump lattice model developed by Boyle (1988) can be used if there are two state variables. Clearly, some of these models may be able to provide solutions to cash flow uncertainty provided this uncertainty is not of an extreme nature and can be resolved within the investment horizon. However, 
they are less able to handle uncertainty that can extend beyond the horizon and which can be unpredictable and extreme. Researchers have combated the presence of extreme cash flows by adapting real options models to handle these conditions ${ }^{4}$. In this paper, we adopt a model that attempts to overcome some of the deficiencies of earlier models. First, and unlike the models using a constant probability assumption, we postulate a stochastic probability model to handle cash flow uncertainties. Second, and in order to analyze the impact of ECFs, we utilize a lattice model with more tranches to accommodate ECFs. This model also differs from the constant discount rate/volatility trinomial tree model used in Boyle (1986).

By definition, ECFs are rare and difficult to predict. The literature has developed "extreme value theory" to assist managerial decision making under extreme conditions (Mandelbrot 1963, 1997). With increased onset of global financial crises (Burnie, De Ridder 2010), the modeling of downside risk (as a semi-variance) under extreme conditions has received more attention (Teversy, Kahneman 1974; Unser 2000). In addition to the traditional benchmarks (the original investment, the risk free rate, and market returns), investors use additional measures to capture downside risk (Veld, Veld-Merkoulova 2008) for evaluation purposes. Managers also invest in negative NPV projects because of overconfidence (Ahmed, Duellman 2013) or agency related issues (Pyo et al. 2012). Instead of acknowledging/correcting their errors, managers sometimes continue to invest in negative NPV projects (Clayton, Reisel 2013). Informational asymmetries exacerbate such problems if managers underestimate the probability and/or the amount of loss if projects fail (Chaplinsky, Haushalter 2010).

Finally, Knight and Pretty (1998) suggest that management actions in managing catastrophic events (or extreme events) play a significant part in how firms recover from these events. They present examples of firms that went bankrupt from extreme events (for example, Valujet after the $1982 \mathrm{crash}$ ) to those that recovered completely after such events (for example, Johnson \& Johnson after the Tylenol poisoning events). To quote (Knight, Pretty 1998), the ability for firms to recover from catastrophic events depends on "the company's ability to deal with the aftermath of the loss" (p. 40). Unstated here is the notion that the company may also need some time to manage the extreme loss problem.

\section{The model and settings}

The Cox et al. (1979) binomial tree framework is used to provide the basis for our simulated based investigation of the managerial decision making impact of ECFs. The real options based methodology provides a perfect platform to examine the impact of the "abandon" decision inherent in sequential investments. The ability and flexibility of assigning actual values to path dependence investment decision make the real options method distinctive from the others managerial decision analysis methods (Adner,

\footnotetext{
${ }^{4}$ These models are described below in section 2 .
} 
Levinthal 2004). Real options methodologies have also been introduced by Fernandes et al. (2012) and Fisch and Zschoche (2012) to model decision making under uncertainty where firms face cash flow turbulence and/or changing environmental landscapes. Finally, the importance of preserving perceived/operational flexibilities in the valuation process has been shown by $\mathrm{Hu}$ et al. (2013).

Furthermore, and unlike the constant probability assumption in the literature, a stochastic probability model is used in this paper to capture future cash flow uncertainty. Also, unlike the Boyle (1986) trinomial tree with the constant discount rate/volatility assumption model, more tranches are introduced into the lattice structure to accommodate both types of uncertainties proposed here. Using Monte Carlo simulations, we provide insights into the specific interaction of the different factors that create extreme losses and those that do not. We will examine the conditions under which retention of a bad project can generate profits for the firm in the long term ${ }^{5}$. We believe that a firm can benefit in the long run from the actions of a manager who is prone towards assumption of greater risks in the short term. We will examine the interplay of a scenario where both types of extremes occur simultaneously, and attempt to provide policy implications for firms.

The specific model used in this paper is a three jump model originally developed by Boyle (1988) and based on the Cox et al. (1979) basic binomial tree model. This model has three possible outcomes for every time period, i.e. up, down and extreme down, and allows us to model ECF situations easily. For instance, if the normal situation is modeled, then the up, down, and extreme down scenarios can be used to capture normal increases in cash flows, decreases in cash flows, and unprecedented decreases in cash flow, respectively. Unprecedented (or extreme) decreases in cash flow can be caused by economic crises, significant technological breakthroughs in the industry, and/or faulty managerial decision making. We next consider the case where managers make continuous capital investment decisions. Project returns, assumed random each period for all periods over the investment horizon, are discounted using a postulated rate. Since returns are assumed stochastic, simulation based methodology is used since analytical solutions are difficult.

Our purpose is to examine returns on investments under two distinct extreme conditions. First, we postulate the presence of three types of managers who behave differently towards risk taking insofar as capital projects are concerned. The first manager is the 'extreme' (or aggressive) manager whose investment strategy is to continue to invest despite negative expected returns ${ }^{6}$. The second manager is assumed to be a rational investor who possesses perfect information with respect to the probability distribution of future cash flows, and is the rational manager making decisions with perfect informa-

\footnotetext{
${ }^{5}$ Likewise, although we do not explicitly examine the case where adoption of a good project can prove disastrous for the firm in the long run, our results provide a basis for inferring that this can be the case. Researchers may examine this issue further.

${ }^{6}$ We will describe the different types of managers postulated for the simulation process more fully later in this section.
} 
tion $^{7}$. Finally, the third manager makes rational decisions with imperfect information ${ }^{8}$. The first manager is the "extreme" manager whereas the third manager is the (typical) rational manager and can be viewed as the "normal" manager. The second manager possesses perfect foresight with respect to the future distribution of cash flows, and is used as a benchmark for comparison purposes.

We next model the second type of extremity as the one involving future cash flows. The first case is one where there is no possibility of ECFs. ECFs are allowed to occur in the second model. Together, we use simulation methodology to examine the interplay between the two types of extremities (the aggressive manager and ECFs) in the paper. We now explicitly document the parameters of the model and the dynamics of the investment decision-making process facing the manager:

1. Each manager (extreme, rational with perfect information, and rational with imperfect information) is assumed to have a reserved belief derived from his specific knowledge related to the project under consideration. The manager assumes that the capital investment will be profitable with a probability $p_{i}$ during period $i$. Thus, there is a probability $\left(1-p_{i}\right)$ that the project will suffer losses.

2. The future probability of the investments being profitable is assumed fixed at $p_{i}^{e}$, and is a function of $p_{i-1}$ and the manager's private knowledge.

3. NPV is calculated $n$ periods into the future based on the generated expected profit probability of the project. Appropriate accept/reject decisions made using NPV criteria will determine project retention or abandonment.

4. It is also assumed that "nature" reveals the probability $p_{i}$. At the end of the period, the gain/loss associated with the investment is realized.

5. The manager uses new information to update old probabilities $p_{i+1}$, i.e. $p_{i+1}^{e}$.

6 . These steps are repeated till the end of the investment horizon.

We also assume implicitly that investors are risk neutral and do not interfere in any way with decisions made by management. In other words, we assume that the manager's decisions are credible and these decisions can be operationalized even if they are viewed as being aggressive by the investor.

Unlike previous studies, we do not assume that $p_{i} \equiv p$ for all $i$, but instead assume that $p_{i}$ is stochastic and identically distributed in $(0,1)$ space for all $i$. Therefore, the future cash flow uncertainty can be examined in this paper. We adopt a discrete approximation for this underlying stochastic process to provide a transparent and computationally efficient model for this valuation problem. All notations used in our analysis are shown in Table 1.

\footnotetext{
${ }^{7}$ This is not to suggest that the manager can never be wrong. In fact, we argue that the only information the manager has is the probability distribution of each outcome, and not the outcome itself. Hence, this type of manager can make mistakes.

${ }^{8}$ In other words, the manager does not have access to the exact probability distribution of future cash flows.
} 
Table 1. Notations

\begin{tabular}{cl}
\hline Notation & \multicolumn{1}{c}{ Meaning } \\
\hline$u$ & Up movement; $1+$ the percentage increase of up movement over each period \\
\hline$d$ & $\begin{array}{l}\text { Down movement; } 1 \text { - the percentage decrease of down movement over each } \\
\text { period }\end{array}$ \\
\hline$d_{e}$ & $\begin{array}{l}\text { Extreme down movement; } 1 \text { - the percentage decrease of extreme down } \\
\text { movement over each period }\end{array}$ \\
\hline$p_{i}$ & Probability of up movement in period $i$ \\
\hline$p_{i}^{e}$ & $\begin{array}{l}\text { Expected probability of up movement since period } i, \text { because of information } \\
\text { asymmetry }\end{array}$ \\
\hline$p_{i, j}$ & Probability of the occurrence of node $(i, j)$ \\
\hline$S_{i}$ & Cash flow (return) in period $i$ \\
\hline$X_{i, j}$ & Expected return of node $(i, j)$ from period $i$ to the end period \\
\hline$C_{i}$ & Cost of investment in each period $i$ \\
\hline$\beta_{i}$ & Down movement tendency parameter in period $i$ \\
\hline$r$ & Discount rate \\
\hline
\end{tabular}

Next, appropriate benchmarks need to be established in order to simulate the decisionmaking process under ECF conditions. Two different benchmarks are established - one to evaluate the behavior of the extreme manager, and the second to evaluate the impact of ECFs, both on firm returns. Hence, we postulate three different types of decision makers (managers) who adopt three different strategies. These managers are, respectively, the uninformed rational manager, the informed manager and the aggressive manager (as described earlier). An uninformed rational manager makes decisions following the dynamics of the decision process listed above. Because of incomplete information about $p_{i}$ available to the manager, the uninformed rational manager has to develop future probabilities $p_{i}^{e}$ based on historical data, $p_{i-1}$, and his judgment of the probability during the previous period, $p_{i-1}^{e}$. An informed manager, however, has knowledge of future probability distributions and is able to use this information to make investment decisions. In contrast, an aggressive manager does not have the knowledge of future probabilities of up/down movements, and moreover does not act rationally. He can still insist on investing despite a negative NPV realization for a given period. The aggressive manager's behavior is characterized as an extreme case, as stated previously 9 .

To conclude the parameterization process, we will provide three explicit variables that we will change exogenously. First, we express exogenous investment costs in each

\footnotetext{
${ }^{9}$ The actual NPV based yardsticks for comparing the different models will be presented after describing the model as it is used in the current paper.
} 
period as a fraction of each period's cash flows, and label the fraction as $\alpha_{i}$ and refer to it as the cost ratio ${ }^{10}$. We will consider the decision-making behavior of each type of manager and for each type of cash flows under different values of $\alpha_{i}$. Next, we will vary the investment horizon from 1 to 15 periods and examine managerial decision-making behavior as a function of the investment horizon. Finally, we will alter the discount rate $(r)$ and examine the results. In the next subsection, the benchmark model process under manager irrationality is outlined, followed by a discussion of the process that incorporates the possibility of extreme cash flows into the previous framework.

\subsection{The benchmark model process under possible manager irrationality}

As stated in (Cox et al. 1979), a binomial lattice may be viewed as a probability tree with binary chance branches. Here the uncertainty lies in the return of the investment in any stage. Initially, we introduce a binary tree model to capture the nature of the decision process, which we label as the benchmark model. In this model, we assume that there are only two possible outcomes, moving up $(u)$ with a probability $p_{i}$ and down $(d)$ with $1-p_{i}$, for the investment in each period $i$ and represents the normal situation $^{11}$. Exogenous investment costs in each period are denoted by $C_{i}$, expressed as a proportion of the period 0 cash flow, i.e. $C_{i}=\alpha_{i} S_{0}$, where $\alpha_{i}$ is the cost ratio and $S_{0}$ the cash flow in period 0 .

We consider an $n$-period investment process. Cash flows will be discounted at the rate of $r$ per period. If the probability of an up movement is $p_{i}$ in period $i$, the expected payoff from the investment for an arbitrary node $j i+2 j=1$ in period $i$ is:

$$
X_{i, j}=p_{i}^{\prime} X_{i+1, j}+\left(1-p_{i}^{\prime}\right) X_{i+1, j+1},
$$

where $X_{i+1, j}$ is associated with an up movement, and $X_{i+1, j+1}$ with a down movement, $p_{i}^{\prime}$ can be $p_{i}$ or $p_{i}^{e}$, based on the type of the manager who makes the decision. If $X_{i, j} \leq 0$, then this node $(i, j)$ has no offspring and implies that the manager will stop investing in the project. The difference between the expected payoff, $X_{i, j}$ and the realized payoff (cash flow), denoted by $S_{i, j}$, on a node $(i, j)$ is not probability-dependent. Knowledge of the location of node $(i, j)$ uniquely identifies the value of $S_{i, j}$, obtained by multiplying any of its predecessor's payoff by $u$, or $d$ (or $d_{e}$ in the extreme model described in the next section). Despite many possible realizations at each stage, we can uniquely identify the historical path. For example, independent of the path actually chosen by nature at any stage (for instance, at stage $i+2$ ), the manager possesses knowledge of the actual

\footnotetext{
${ }^{10}$ The variable "cost ratio" is thus an indicator of investment cost in each period. In the model we assume that new costs related to the project surface in each period. In order to preserve tractability, we postulate that these new costs are functions of the initial investment $\mathrm{I}_{0}$. We model investment uncertainty over time by changing the alpha ratio and studying the impact of changing cost ratios on NPVs. Hence, once alphas are exogenously fixed, they remain constant for the duration of the simulation runs. By changing alphas, we model investment cost uncertainty. Since we change alphas exogenously, for each simulation run, these costs are assumed fixed.

${ }^{11}$ As shown in Figure 1, the outcome resulting from moving up (u) and then down (d) in value is the same as the outcome from moving down $(\mathrm{d})$ and then up $(\mathrm{u})$. Thus, this probability tree is recombined, since there are numerous paths to the same outcomes, which significantly reduces the number of nodes in the lattice.
} 
node being realized, as shown in Figure 2. Hence, for period $i+3$, the manager has only two choices to worry about. If $S_{i}$ denotes the realized payoff for period $i$, it can be shown from Figure 2 that $S_{i+1}=S_{i+1,1}=u S_{i}$, and $S_{i+2}=S_{i+2,2}=d S_{i+1}$, for all $i$.

The probability of any node $j$ in period $i$ can be determined by a probability extension of lower order, given by the following formula:

$$
p_{i, j}=\left\{\begin{array}{cl}
\prod_{x=1}^{i} p\left(S_{i, j} \mid S_{i-1, j}\right) & \text { if } j=1 \text { or } i \\
\prod_{x=1}^{i}\left[p\left(S_{i, j} \mid S_{i-1, j}\right)+p\left(S_{i, j} \mid S_{i-1, j-1}\right)\right] & \text { otherwise. }
\end{array}\right.
$$

It can be seen from (2) that the probability of any final branch on the decision tree is a cumulative conditional function. Hence, although volatility tends to decrease with time, the transition process assumed in our model is random and memory less, i.e., it's a Markovian process ${ }^{12}$.

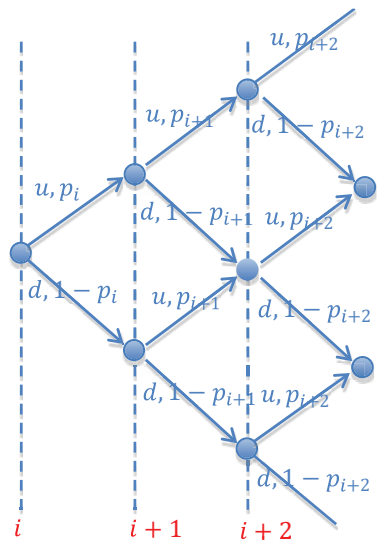

Fig. 1. Decision tree of the benchmark model

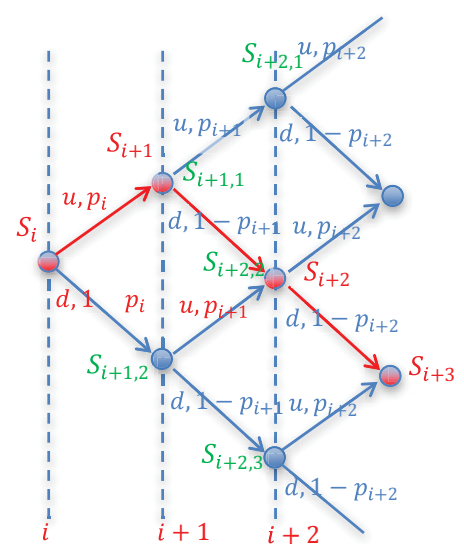

Fig. 2. An example of the benchmark model

The objective is to determine which strategy generates the highest payoff for the firm. To achieve this, we compute the NPV of total returns simulated for each type of manager (the uninformed, the informed, and the aggressive). Assuming that arbitrage opportunities do not exist, the value of the investment option today is determined by the expected future payoff discounted at the risk-free rate:

$$
\mathrm{NPV}=\sum_{i=0}^{k} \frac{S_{i}-C_{i}}{(1+r)^{i}},
$$

where $k$ is the terminating period for the investment, and $r$ is the discount factor. The NPVs generated based on extreme, rational with imperfect information as well as ra-

${ }^{12}$ However, the probability distribution at any point in time is exogenously determined. The impact of changes in this function on results is left for future research. 
tional with perfect information strategies are respectively denoted by $\mathrm{NPV}_{X}, \mathrm{NPV}_{I I}$ and $\mathrm{NPV}_{P F}$. Obviously, since we postulated three different types of managers, the simulated NPVs of total returns over time are expected to be different in the long run. Our purpose is to compare these three NPV's using results generated through Monte Carlo simulation.

\subsection{Extreme value model: the possibility of extreme cash flows}

The above model incorporates only one type of extremity, namely, manager irrationality. In this section, we now add the possibility of ECFs and refer it as the Extreme Value Model (EVM). Figure 3 provides the probability schematic for the EVM. As shown in Figure 3, in addition to the possibility of a good cash flow outcome (moving up), there are two bad outcomes $\left(d\right.$ and $d_{e}$ ) that can possibly occur in each period. $d$ captures the normal downward movement outlined earlier, while $d_{e}$ captures the possibility of an extreme loss, and $d_{e} \ll d$. Assuming that the probability of the cash flow moving up is $p_{i}$, the total probability of negative cash flows is $1-p_{i}$. Conditional on the cash flow realizations being negative, the probability of smaller (normal) losses is portrayed by probability $\beta_{i}$, with $1-\beta_{i}$ being the conditional probability of an extremely negative cash flow. Therefore the probabilities of $u, d, d_{e}$ movements in period $i$ are, respectively, $p_{i}, \beta_{i}\left(1-p_{i}\right),\left(1-\beta_{i}\right)\left(1-p_{i}\right)$.

As with the benchmark case presented earlier, the probability of any node $j$ in period $i$ can be determined by a probability extension of lower order, given by the following formula:

$$
p_{i, j}=\prod_{x=1}^{i} p\left(S_{i, j} \mid S_{i-1, \frac{j}{3}}\right) .
$$

Clearly, the probability of the occurrence of any node depends solely on its own unique father node, as shown in Figure 3.

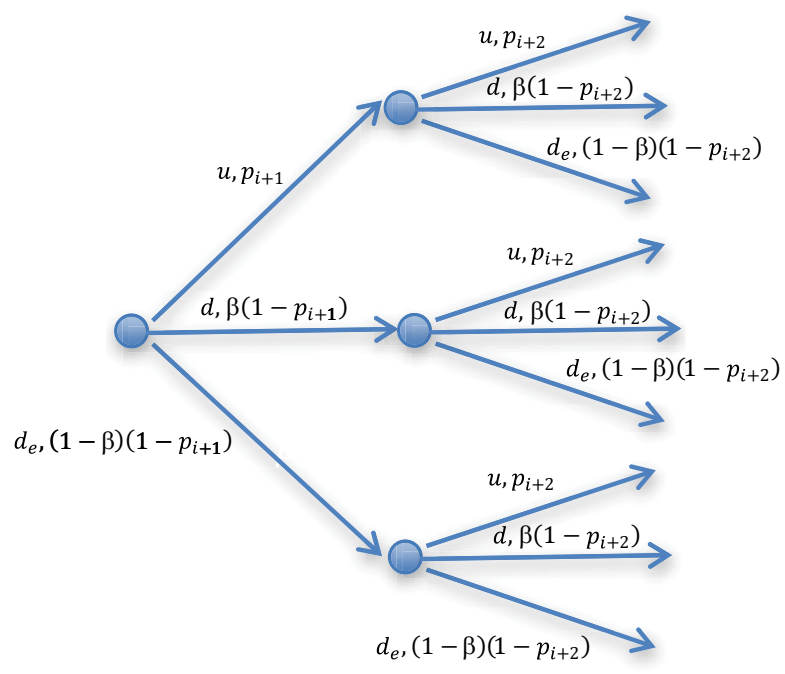

Fig. 3. Trinomial probability tree of extreme value model 
In the trinomial probability model of Figure 3, we do not assume that $d_{n}^{2}=u \times d_{e}$. This implies that a conventional trinomial tree cannot be developed analytically. However, since $u \times d_{e}=d_{e} \times u$, the number of branches remains finite.

The expected investment payoff for an arbitrary node $j$ in period $i$ is given by:

$$
X_{i, j}=p_{i}^{\prime} X_{i+1,3 j-2}+\beta_{i}\left(1-p_{i}^{\prime}\right) X_{i+1,3 j-1}+\left(1-\beta_{i}\right)\left(1-p_{i}^{\prime}\right) X_{i+1,3 j},
$$

where $X_{i+1,3 j-2}$ is associated with an up movement, $X_{i+1,3 j-1}$ a normal down movement, and $X_{i+1,3 j}$ with an extreme down movement; $p_{i}^{\prime}$ can be $p_{i}$ or $p_{i}^{e}$, based on the type of the manager who makes the decision. If $X_{i, j} \leq 0$, then this node $(i, j)$ has no offspring. Table 2 presents the different types of normal and extreme situations investigated in the paper.

Table 2. Different types of cash flow situations and manager extremity analyzed in the paper

\begin{tabular}{lll}
\hline \multirow{2}{*}{ Type of manager } & \multicolumn{2}{c}{ Cash flow events } \\
\cline { 2 - 3 } & \multicolumn{1}{c}{ Normal } & \multicolumn{1}{c}{ Extreme } \\
\hline Uninformed rational (the normal manager) & $\mathrm{NPV}_{I I}^{B}$ & $\mathrm{NPV}_{I I}^{E}$ \\
\hline Informed rational (the perfect foresight manager) & $\mathrm{NPV}_{P I}^{B}$ & $\mathrm{NPV}_{P I}^{E}$ \\
\hline Aggressive, occasionally irrational (the extreme manager) & $\mathrm{NPV}_{X}{ }^{B}$ & $\mathrm{NPV}_{X}^{E}$ \\
\hline
\end{tabular}

\section{Numerical analysis}

For the uninformed rational manager and the aggressive manager, since they don't know the probability of up or down movements for each period, they adopt the following schematic to develop the probability trees based on the historical path and their own judgments. Their expected probability realization is given by the following formula:

$$
p_{i}^{e}=\frac{1}{2}\left(p_{i-1}^{e}+p_{i-1}\right) \text {. }
$$

We apply the Monte Carlo method to simulate the investment process with $p_{i} \sim U\left(\max \left(p_{i-1}-\delta, 0\right), \min \left(p_{i-1}+\delta, 1\right)\right), \forall i \geq 1,1>\delta>0$. The reason we assume that $p_{i}$ is uniformly distributed in $\left(\max \left(p_{i-1}-\delta, 0\right), \min \left(p_{i-1}+\delta, 1\right)\right)\left(\right.$ instead of $\left.p_{i} \sim U(0,1)\right)$, is to avoid sudden drastic changes in probability between adjacent periods. For example, if the economy is good, the probabilities of up movements should be consistently higher in consecutive periods than other times. The smaller the $\delta$ value, the more consistent will be the probability outcome. In our simulation, we set $\delta=.5$ so that in adjacent periods the probability will not record extreme high or low values.

\subsection{Benchmark model and results: normal cash flows with possible manager irrationality}

We first examine the benchmark model that only involves two options of movement for each stage or period. Investment $\operatorname{cost} C_{i}$ is simplified to $C=\alpha S_{0}$ for all periods. We also restrict the percentage increase in the stock price to be $u=1.2$ and the percentage decrease to be $d=0.83$. Without loss of generality, the maximum depth of the investment horizon is assumed to be 15 . We use NPV differences between extreme and rational with 
imperfect information strategies and NPV differences between extreme, $\mathrm{NPV}_{X}-\mathrm{NPV}_{I I}$, and rational with perfect information strategies, $\mathrm{NPV}_{X}-\mathrm{NPV}_{P I}$, as our major measures of performance for the firm.

\subsubsection{Cost ratio}

Figure 4 presents a series of NPV differences, $\mathrm{NPV}_{X}-\mathrm{NPV}_{I I}$ under different values of the cost ratio $\alpha$. Based on these graphs, the extreme strategy dominates the rational with imperfect information strategy, as the investment horizon increases, especially when $r$ is close to 0. Aggressive decisions are more likely to pay off under a deeper investment horizon, and it's almost certain with a long investment horizon. As $\alpha$ increases, the advantage of the extreme strategy over the rational with imperfect information strategy increases initially and decreases after a certain threshold. To generalize, extreme decisions are less preferable when the cost of investment is either too small or too big. This finding is also supported by simulation results we obtained from investigating the NPV difference, $\mathrm{NPV}_{X}-\mathrm{NPV}_{P I}$. There seem to be no significant differences between the outcomes with or without perfect information as long as the decision maker is rational.

\subsubsection{Investment horizon}

The importance of the time horizon in investment decisions has been widely discussed in finance (Block 1972). Except under the special case when $n=2$, and as depicted in any of the graphs in Figure 5, the extreme strategy dominates the rational with imperfect
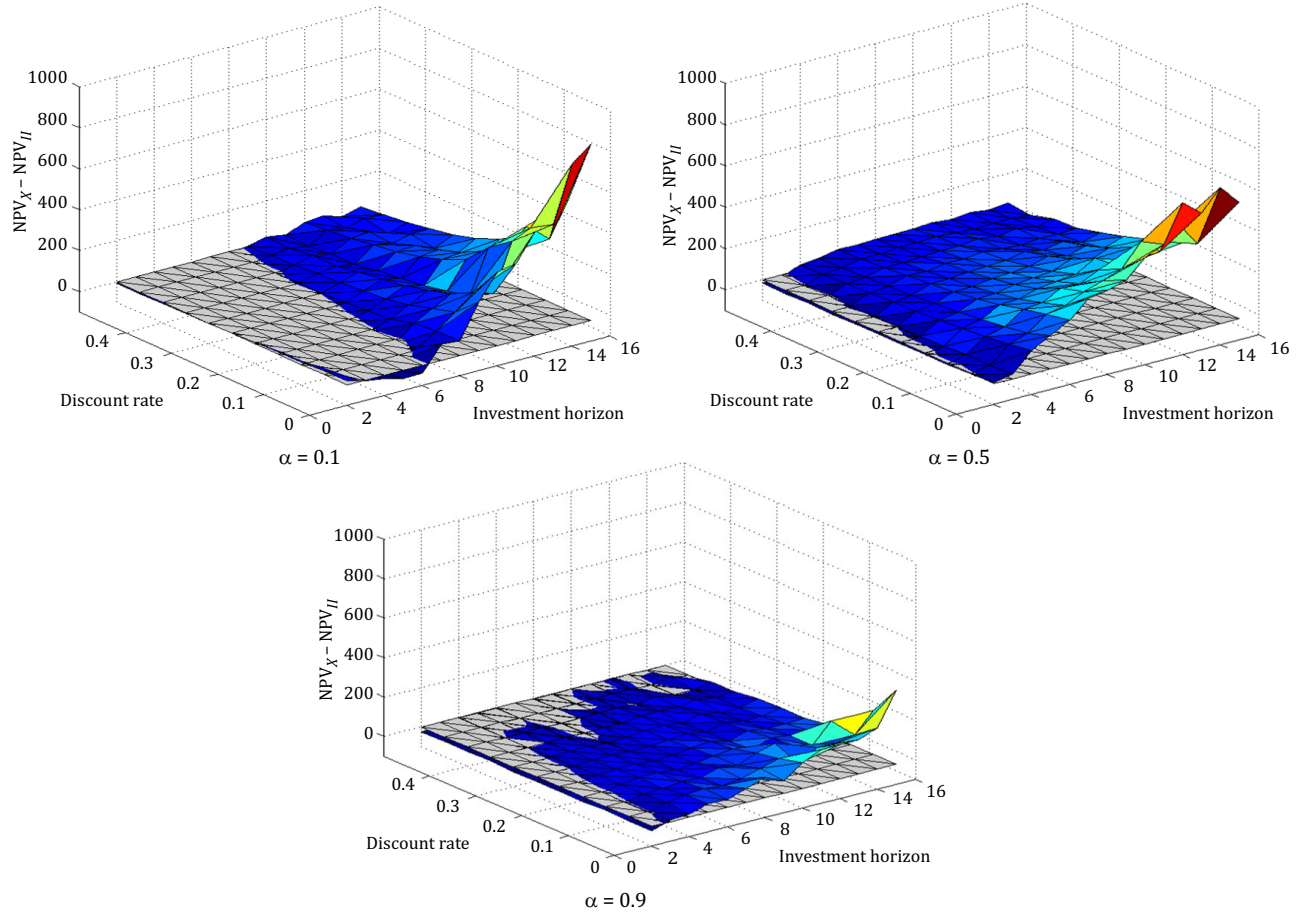

Fig. 4. Differences in NPV, $\left(\mathrm{NPV}_{X}-\mathrm{NPV}_{I I}\right)$ under different cost ratios; imperfect information strategies 
information strategy when the cost ratio is far from its two extremes (i.e, when $\alpha=0$, or 1). A smaller discount rate strengthens this dominance. From $n=2$ through $n=12$, the advantages of an extreme strategy appear increasingly significant. In particular, when $n=12$, most of the surface of $\mathrm{NPV}_{X}-\mathrm{NPV}_{I I}$ is above the 0 -plane, implying that the extreme strategy is preferred to the other strategies here.
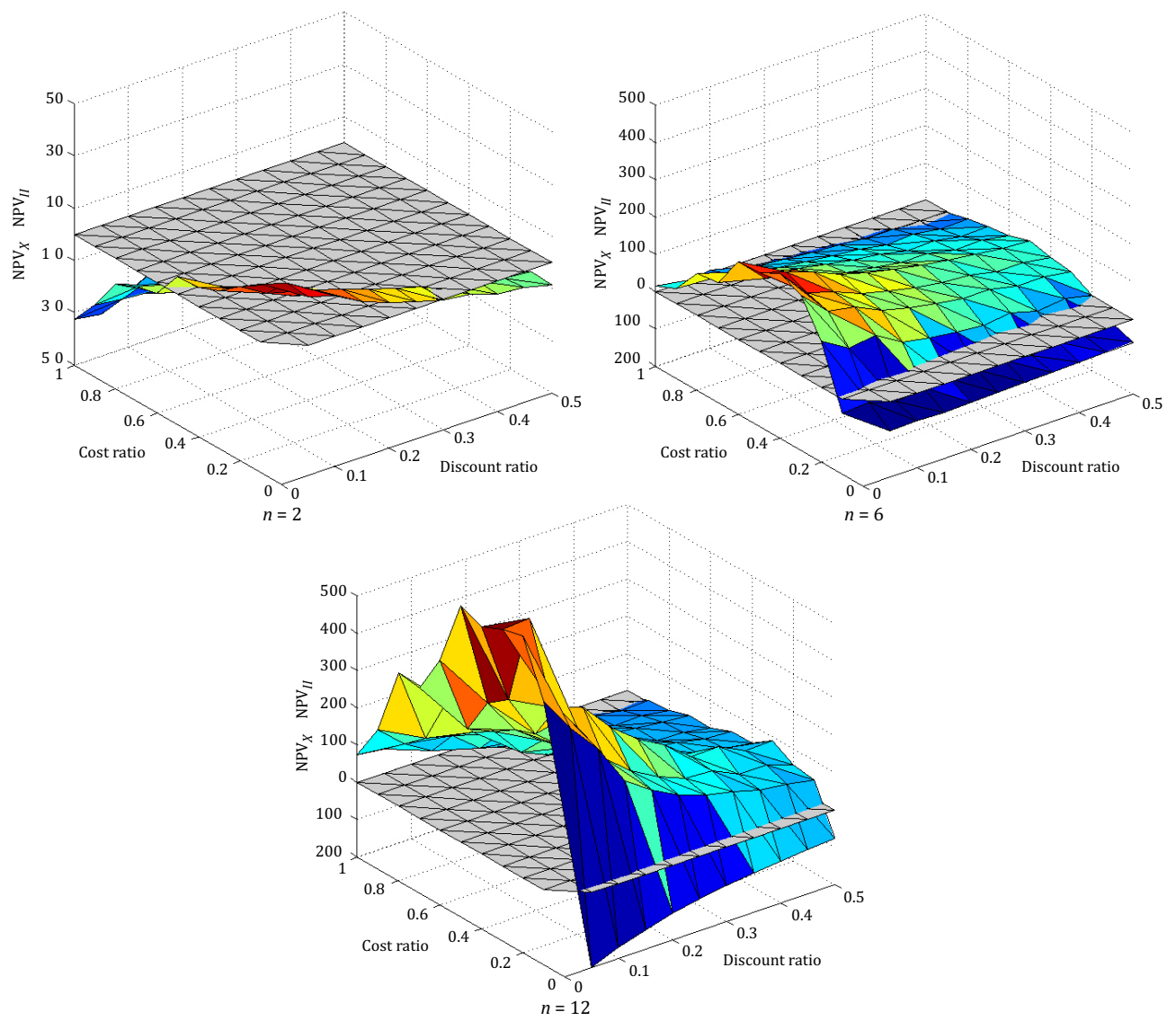

Fig. 5. Differences in NPV, $\left(\mathrm{NPV}_{X}-\mathrm{NPV}_{I I}\right)$ under different investment horizons; imperfect information strategies

\subsubsection{Discount rate}

Discount rates are related to the marginal rate of substitution between current and future consumption, and may depend on factors that determine the marginal utility that include time preferences (Benzion et al. 1989). Researchers have suggested that firms should not pay today if catastrophic events are expected to occur in the very distant future, even thoug the cost of insurance is very small (Lind 1990). The simulation results for changing discount rates presented graphically in Figure 6 suggest that except when $r=$ 0 , all graphs display a concave-like structure in the investment horizon cross section. As $r$ increases, there are more instances where $\mathrm{NPV}_{X}-\mathrm{NPV}_{I I}$ becomes negative. Hence, a larger discount rate will make the rational strategy more valuable. 

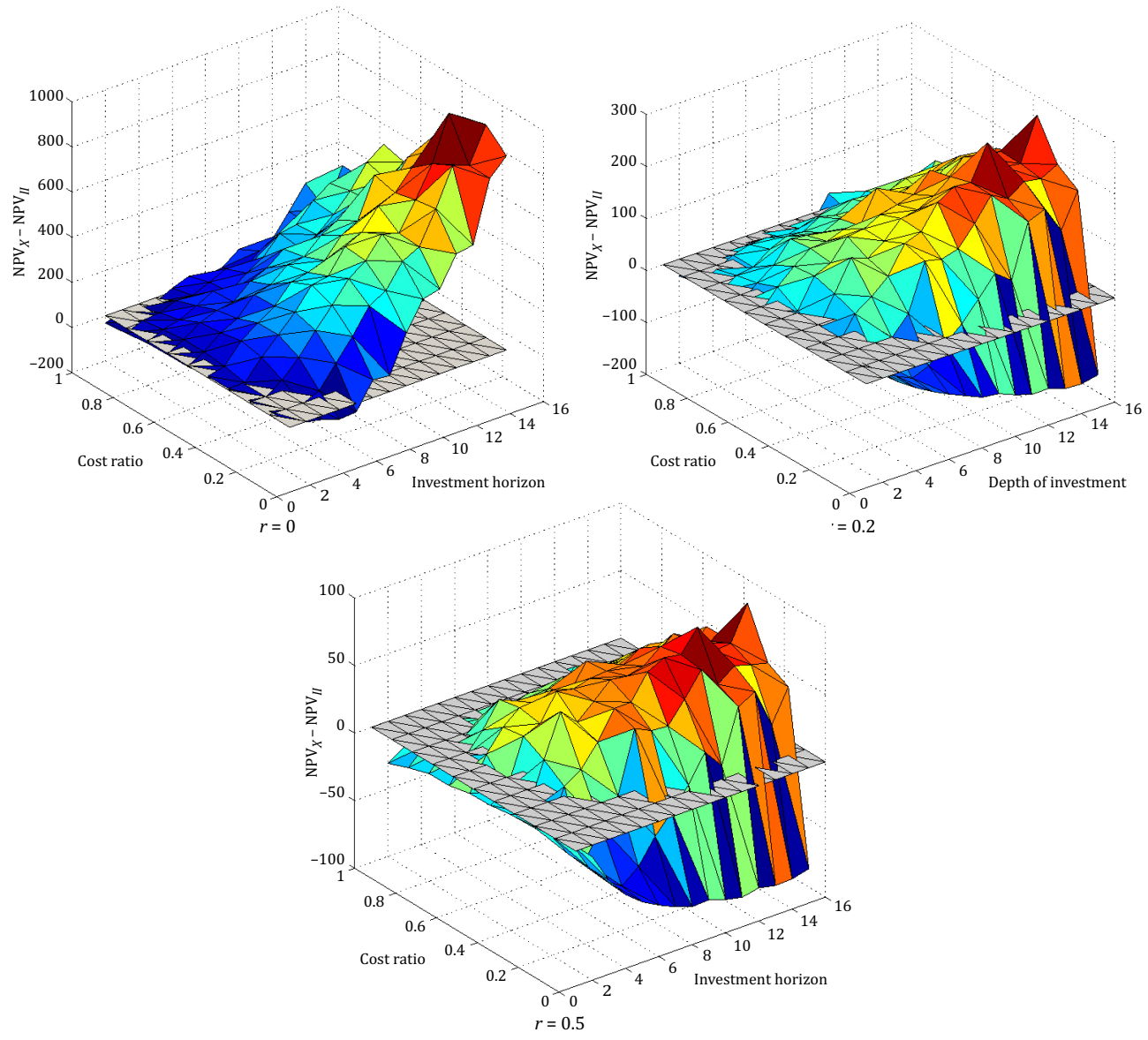

Fig. 6. Differences in NPV, $\left(\mathrm{NPV}_{X}-\mathrm{NPV}_{I I}\right)$ under different discount rates, $r$; imperfect information strategies

Figure 7 exhibits cross-sectional views of $\mathrm{NPV}_{X}-\mathrm{NPV}_{I I}$ in greater detail. With a small discount rate (for example, when $r=0.1$ ), the extreme strategy dominates other strategies especially when the investment horizon increases, but this domination gets attenuated as $r$ increases. Given fixed values for $r$ and $n$, the curve of $\mathrm{NPV}_{X}-\mathrm{NPV}_{I I}$ is roughly quasi-concave with respect to $\alpha$. Therefore, we can theoretically find an investment $\operatorname{cost} \alpha^{*}$ which maximizes the advantage of an extreme strategy ${ }^{13}$.

Overall, the results under normal cash flows and possible manager irrationality lead to the following conclusions: 1) Firms with extreme managers and normal cash flow patterns do not suffer losses in most cases, but especially with low cost ratios and/or long horizons. 2) Firms fare better with rational managers for high discount rate or short horizons. 3) Manager irrationality will have minimal impact on firm level profitability for long-term projects with long horizon, and advantages decrease with cost ratio increases.

\footnotetext{
${ }^{13}$ We leave the investigation of this optimal cost for future research.
} 

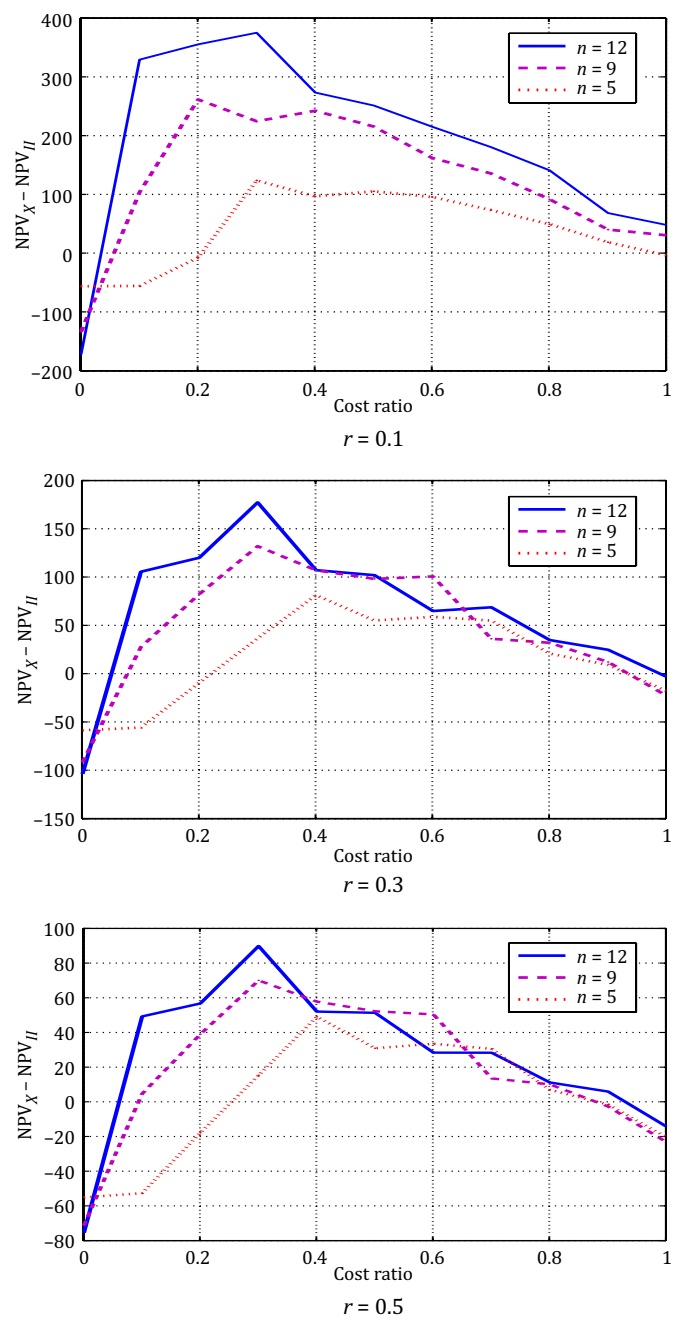

Fig. 7. Cross-sectional view of difference in NPV, $\left(\mathrm{NPV}_{X}-\mathrm{NPV}_{I I}\right)$ under various discount rates, $r$; imperfect information strategies

\subsection{Extreme value model and results: modeling extreme cash flow situations}

In this section, we introduce ECFs into the modelling process. As before, we allow three types of managers and postulate investment cost $C_{i}$ as $C=\alpha S_{0}$ for all periods. We assume $\beta_{i}=\beta=0.8$ for all periods for simplicity. Next, the maximum investment horizon depth is assumed to be 13 and the percentage increase in the stock price is assumed to be $u=1.2$. Similarly, we assume that the percentage decrease is $d=0.83$, and the percentage decrease in extreme cash flows to be $d_{e}=0.083$. As before, we use the differences in NPV, namely, $\mathrm{NPV}_{X}-\mathrm{NPV}_{I I}$ and $\mathrm{NPV}_{X}-\mathrm{NPV}_{P I}$, as our major measure of performance. Finally, we will examine the impact of ECF changes under three control variables, namely, cost ratios, investment horizons, and discount rates. 
As indicated in an earlier section, there is a chance $\left(1-\beta_{i}\right)\left(1-p_{i}^{\prime}\right)$, albeit slim, that the investment will go extremely bad ${ }^{14}$. The importance of investigating this model is twofold. On the one hand, for all cases where extreme losses do not occur, we can check if the results are similar to what was observed under the benchmark model. Clearly, even under these scenarios, it is possible that extreme down movements may never be realized. However, there is always a chance (even if small) of its occurrence. Hence, we would like to provide decision making strategies for firms when facing ECFs.

\subsubsection{Cost ratio}

Figure 8 presents results of these runs. The extreme strategy begins to lose its dominance over the normal case as cash flows become more extreme. With low cost ratios, the
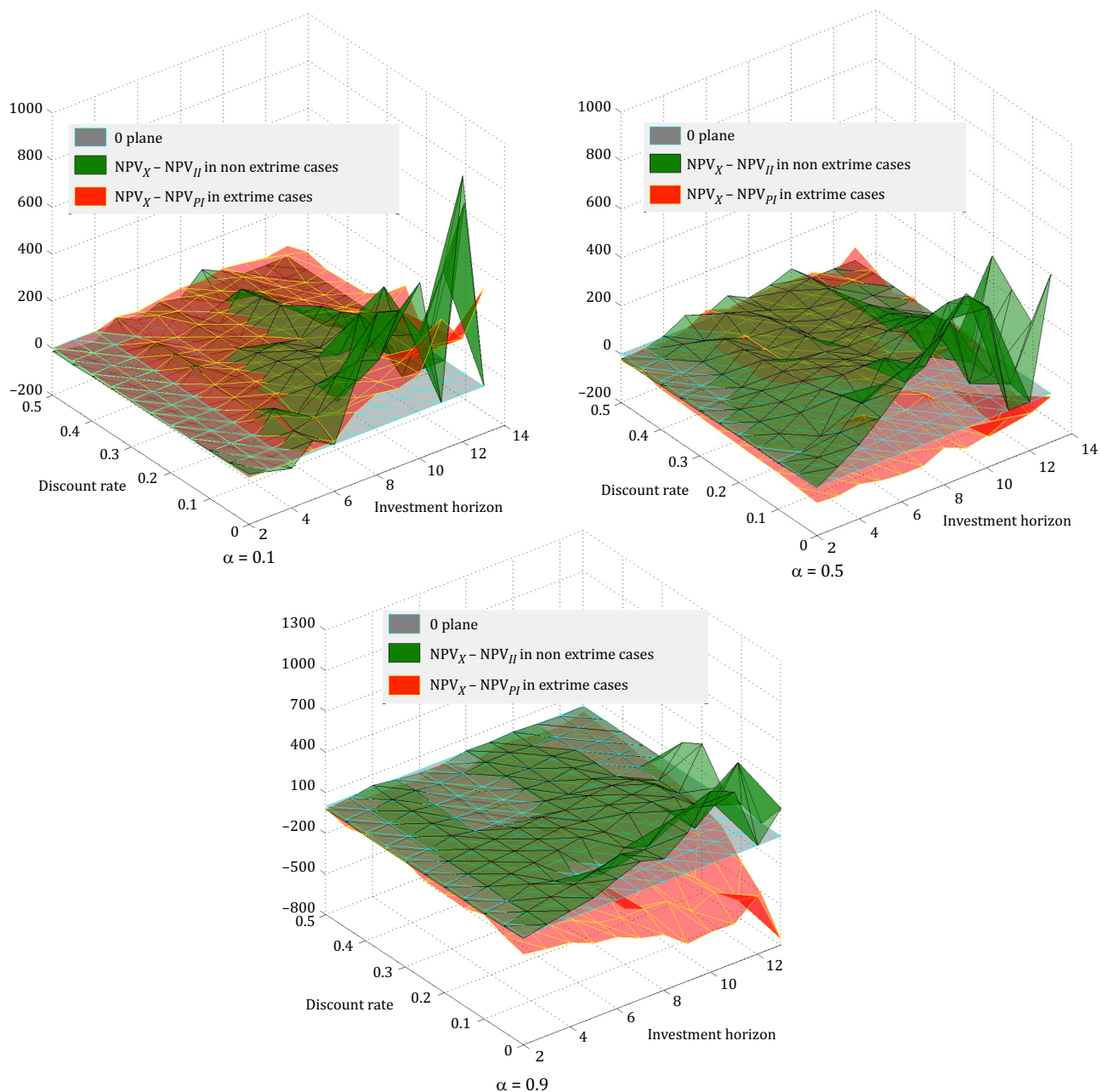

Fig. 8. Differences in NPV, $\left(\mathrm{NPV}_{X}-\mathrm{NPV}_{I I}\right)$ under different cost ratios; with/without extreme cases

\footnotetext{
${ }^{14}$ If not, this investment project may be easily declined at the outset.
} 
extreme strategy is more preferable for extreme cases than for non-extreme cases. A long investment horizon and a high discount rate can strengthen the superiority of the extreme strategy for extreme cases. The extreme strategy is more likely to dominate the rational strategy if the investment cost is within the non-extreme ranges. The advantages of the extreme strategy over the rational strategy become less clear with long investment horizons and small discount rates. The extreme strategy with extreme cases dominates other strategies with small cost ratios, but this dominance decreases rapidly with increases in cost ratios. When extreme down movement occurs, and as investment costs increase, the rational strategy becomes the preferred strategy.

\subsubsection{Investment horizon}

Figure 9 presents simulation results when the investment horizon is changed. Specifically, the difference $\left(\mathrm{NPV}_{X}-\mathrm{NPV}_{I I}\right)$, with or without extreme cases, is presented. The extreme strategy is more likely to dominate over longer horizons, for both normal and ECFs.

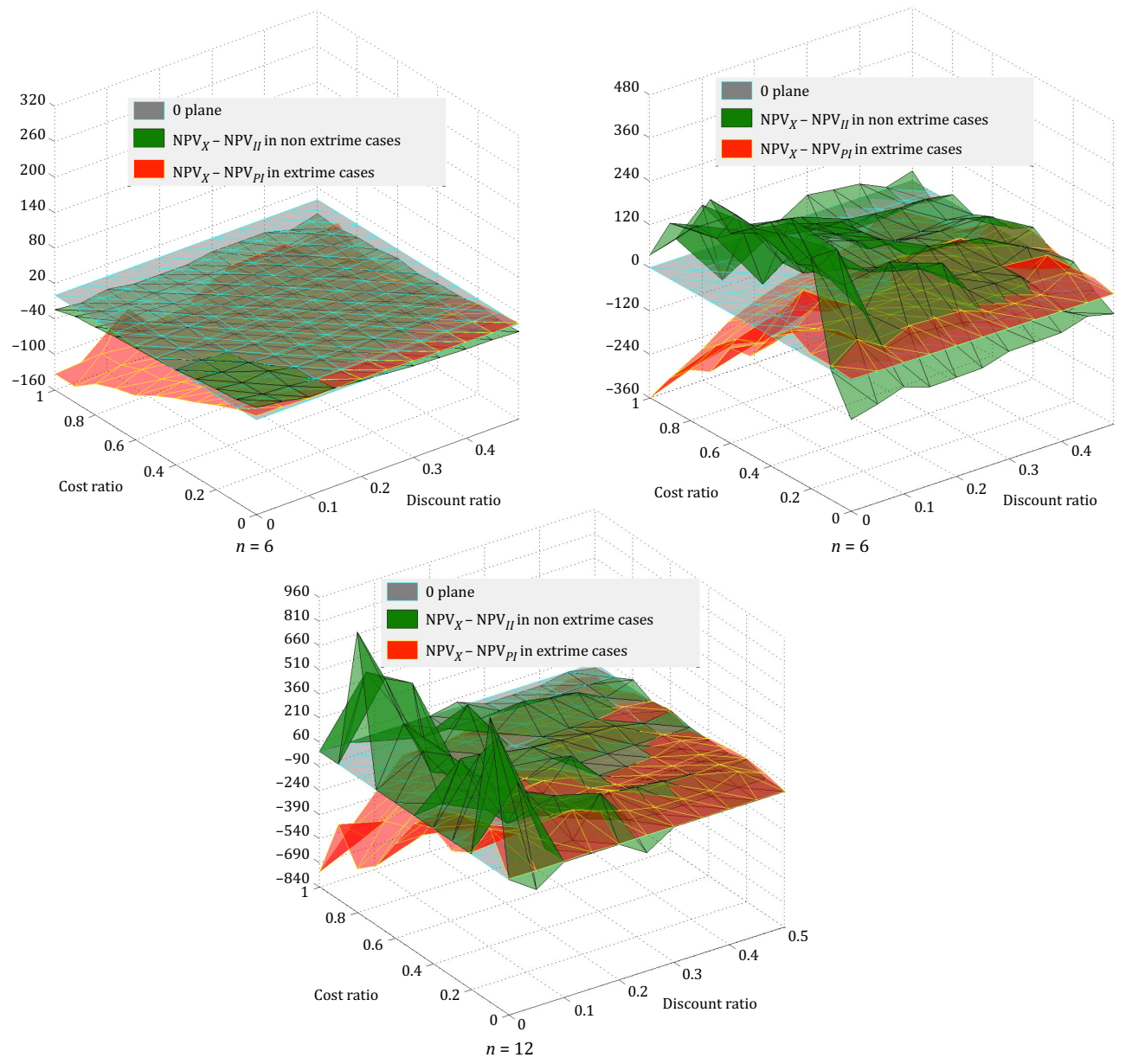

Fig. 9. Differences in NPV, $\left(\mathrm{NPV}_{X}-\mathrm{NPV}_{I I}\right)$ under different investment horizons; with/without extreme cases 
The extreme strategy dominates the rational strategy when extreme cases occur over the long term, especially if small cost ratios occur at the same time. This dominance is more profound when only normal cash flows are considered, for small discount rates. This advantage extends to intermediate cost ratios as well. For ECF cases, the extreme strategy dominates for small cost ratios and high discount rates.

\subsubsection{Discount rate}

In this section, we now explore how discount rate changes affect the dominating strategy. Figure 10 presents the results from these runs. One important insight is that with normal cash flows, the extreme strategy loses its dominant position with increases in the discount rate, but not under ECF conditions. With ECFs, the extreme strategy maintains its dominance even with increases in the discount rate, and this result can easily be rationalized. A high discount rate reduces both positive and negative cash

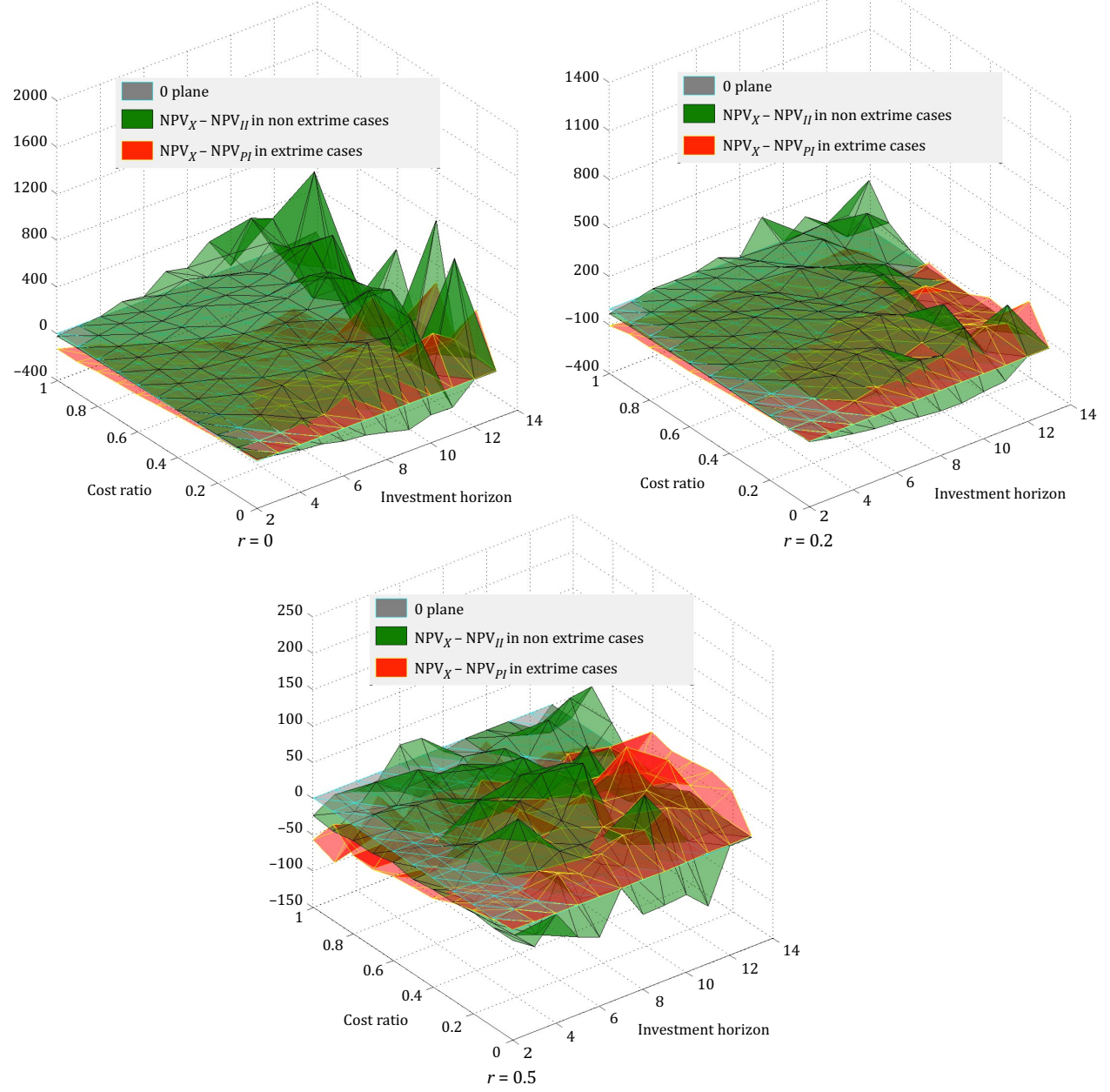

Fig. 10. Differences in NPV, $\left(\mathrm{NPV}_{X}-\mathrm{NPV}_{I I}\right)$ under different discount rates; with/without extreme cases 
flows in a similar manner for the entire horizon. Given this, the manager may be less worried about ECFs with high discount rates since now the manager can assume more risk without penalty. In the long run, this strategy pays off. Finally, extreme strategy maintains dominance with extended investment horizons and when cost ratios are high or low.

Table 3 outlines the (generally) best strategies when manager irrationality and/or when extreme cash flow situations are present ${ }^{15}$. These situations are compared to the "normal" situation when managers are assumed to make decisions with imperfect information. The major message is that firms can benefit under both of the extreme cases.

Table 3. Which strategy is more likely to dominate

\begin{tabular}{llll}
\hline \multicolumn{1}{c}{ Cash flow type } & \multicolumn{1}{c}{ Control variables } & \multicolumn{1}{c}{ Small } & \multicolumn{1}{c}{ Large } \\
\hline Normal cash flows & Cost Ratio & Aggressive & Rational \\
\cline { 2 - 4 } & Investment Horizon & Rational & Aggressive \\
\cline { 2 - 4 } & Discount Rate & Aggressive & Rational \\
\hline Extreme cash flows & Cost Ratio & Aggressive & Rational \\
\cline { 2 - 4 } & Investment Horizon & Rational & Aggressive \\
\cline { 2 - 4 } & Discount Rate & Rational & Aggressive \\
\hline
\end{tabular}

Based on the simulations under ECF, firms can be better off with an extreme manager when it faces ECFs under many circumstances. An extreme manager's strategies to assume risks can pay dividends for firms facing long term ECF situations. Simulations reveal that the NPVs with an irrational manager dominate the NPVs with a rational manager with imperfect information for a variety of situations.

\subsubsection{The terminal evolution of decision variables}

Managers have the option to continue/terminate projects at any point within the investment horizon. Defining "decision depth" as the number of periods that a manager continues investment in a project, Figure 11 presents simulation results where decision depths are measured under various values of discount rates and investment horizons for both normal and ECFs. Based on these results, it seems that the decision depth is generally less under ECFs than under normal cash flows. Moreover, there seems to be a greater degree of randomness in decision depth values for normal cash flows than for ECFs. These results are intuitive - ECFs and higher discount rates severely inhibit depth $^{16}$.

The results of the simulation runs involving depth measured relative to the investment horizon (the decision depth ratio) are presented in Figure 12. Not surprisingly, the

\footnotetext{
${ }^{15}$ Note that these conclusions are generally valid, but not always so.

${ }^{16}$ Similarly, large cost ratios reduce the decision depth and the decision depth ratio for both types of cash flows.
} 


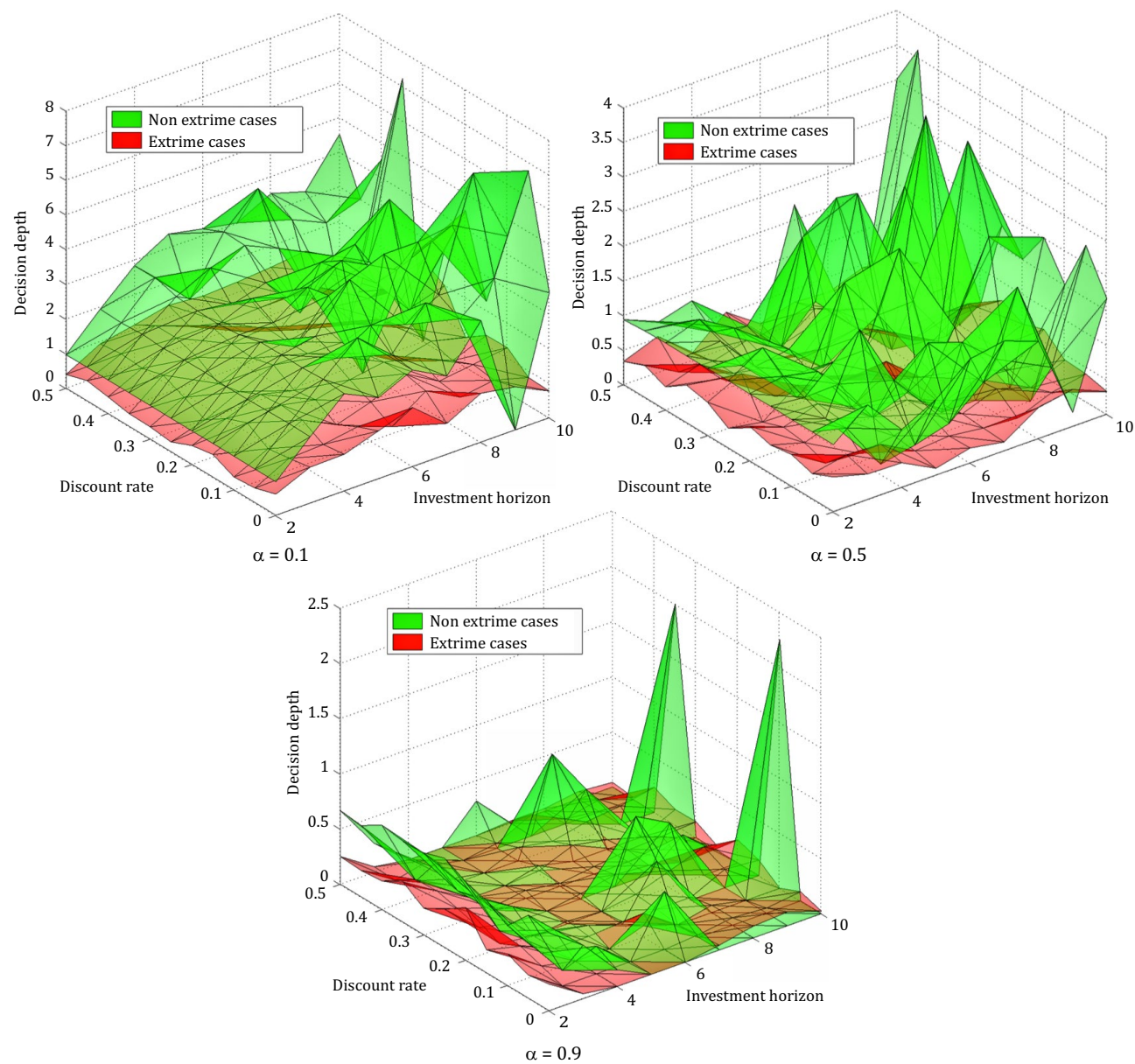

Fig. 11. Decision depth under different uncertainty scenarios, with and without extreme cases

results and the conclusions are similar to what was reported earlier - larger discount rates/cost ratios/investment horizons shorten the decision depth ratios. In other words, when the investment horizon increases, the rational manager is more likely to be conservative. ECFs also inhibit the ratio since with extreme cases it seems likely that the projects will be rejected earlier than under normal cash flows.

\section{Conclusions, managerial insights and suggestions for further research}

Uncertainty plays an important role in shaping firm choice involving continuing/ terminating sequential projects. Given appreciable uncertainty about cash inflows (especially extremely negative cash inflows), a firm may face the unpleasant prospect of needing to curtail operations significantly, or, even worse, file for bankruptcy. In this paper, we provide simulation runs that deal with volatility, namely the possibility that firms face extreme cash flows. In addition, we also incorporate the volatility associated with firm project managers behaving rationally (perfectly/imperfectly) or aggressively. 

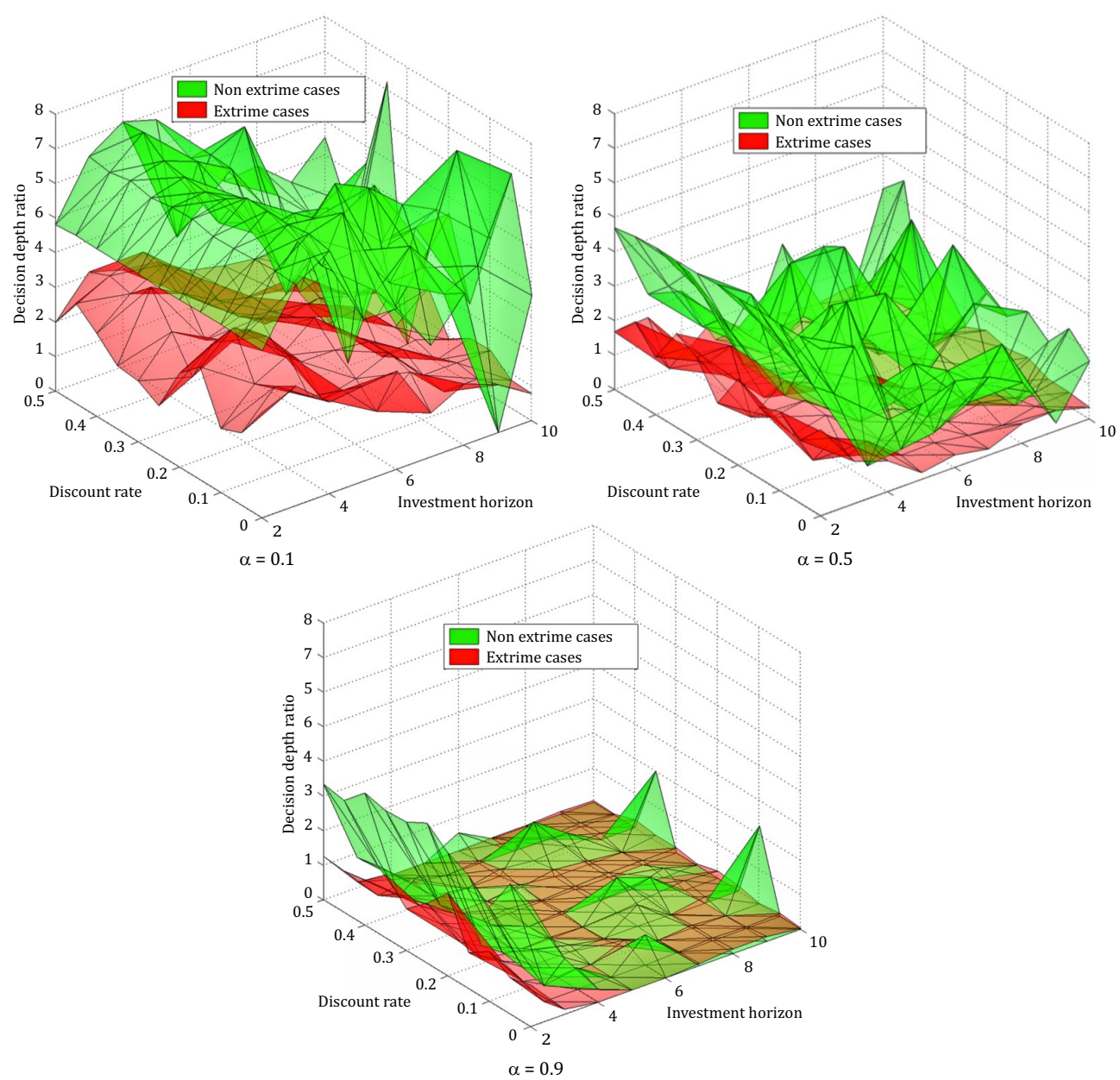

Fig. 12. Decision depth under different uncertainty scenarios, with and without extreme cases

The major message of the simulation runs conducted in this paper is that firms who hire aggressive managers can generally reap long term dividends when the cost ratios and/ or discount rates are small, or the investment horizons are high, if cash flows follow normal patterns. With small cost ratios/discount rates, accepting unprofitable projects in the short run may not prove disastrous since the firm may easily recover in the long run. Long investment horizons allow firms' better opportunities for future long term positive cash flows, even if the other two control variables are high. These possibilities may have been missed by a rational/imperfect information manager who may have terminated the project once it reaches a threshold negative cash flow level. These long-term profits may be captured by the aggressive manager under certain circumstances.

The results for ECF cases suggest that the firm's NPV with an aggressive manager also dominates those under rational strategies under a wide range of cost ratio/investment horizon/discount rate assumptions. This is a counter-intuitive result. The longer horizon (or 
the low cost ratio/discount rates) also provides the opportunity for positive cash flows in the long term to even overcome ECFs. Rational or imperfect managers' rejection of short term negative projects also implies that they lose the opportunity to participate in possible recovery in future years, even with ECF possibilities. Clearly, firms must first determine its exposure to ECF. If this possibility exists, and if the investment horizon is large, the firm may benefit by quietly encouraging its managers to assume greater risks.

The model of this paper can be extended in at least three ways. Our model that captures extreme negative cash flows may be extended to accommodate the possibility of positive extreme cash flows. We believe that this scenario will prove further the benefits of hiring aggressive managers. Second, we have not modeled the impact of the nature of market competition on the results. If firms are operating in a monopoly/oligopoly environment, it is possible that they enjoy the benefits of a longer horizon with less competition to allow for aggressive managers' risk taking behavior to bear fruit eventually in the form of positive cash flows for the firm. However, in competitive industries, firms may not have the luxury of investing in projects with losses in the short term. The reduced barriers to entry into the industry force competitive firms to reject unprofitable projects in the short run with greater frequency than for firms with strong barriers to entry. The degree of market concentration can be modeled as another variable and its impact on the results examined. Finally, the model assumes that the probability distribution was exogenously determined and fixed at each point in time. Relaxing this assumption provides fruitful avenues for further research.

\section{References}

Abel, A. B.; Dixit, A. K.; Eberly, J. C.; Pindyck, R. S. 1996. Options, the value of capital, and investment, The Quarterly Journal of Economics 111(3): 753-777.

http://dx.doi.org/10.2307/2946671

Adner, R.; Levinthal, D. A. 2004. What is not a real option: considering boundaries for the application of real options to business strategy, Academy of Management Review 29(1): 74-85.

Ahmed, A. S.; Duellman, S. 2013. Managerial overconfidence and accounting conservatism, Journal of Accounting Research 51(1): 1-30. http://dx.doi.org/10.1111/j.1475-679X.2012.00467.x

Benzion, U.; Rapoport, A.; Yagil, J. 1989. Discount rates inferred from decisions: an experimental study, Management Science 35(3): 270-284. http://dx.doi.org/10.1287/mnsc.35.3.270

Black, F.; Scholes, M. 1973. The pricing of options and corporate liabilities, The Journal of Political Economy 81(3): 637-654. http://dx.doi.org/10.1086/260062

Block, F. E. 1972. Time horizon, Financial Analysts Journal 28(5): 30-62.

http://dx.doi.org/10.2469/faj.v28.n5.30

Boyle, P. P. 1986. Option valuation using a three-jump process, International Options Journal 3(1): 7-12.

Boyle, P. P. 1988. A lattice framework for option pricing with two state variables, Journal of Financial and Quantitative Analysis 23(1): 1-12. http://dx.doi.org/10.2307/2331019

Brennan, M. J.; Schwartz, E. S. 1985. Evaluating natural resource investments, Journal of Business 58(2): 135-157. http://dx.doi.org/10.1086/296288

Burnie, D. A.; De Ridder, A. 2010. Far tail or extreme day returns, mutual fund cash flows and investment behaviour, Applied Financial Economics 20(16): 1241-1256.

http://dx.doi.org/10.1080/09603107.2010.489885 
Chang, C. C.; Chen, M. Y. 2012. Re-examining the investment-uncertainty relationship in a real options model, Review of Quantitative Finance and Accounting 38(2): 241-255.

http://dx.doi.org/10.1007/s11156-011-0227-2

Chaplinsky, S.; Haushalter, D. 2010. Financing under extreme risk: contract terms and returns to private investments in public equity, Review of Financial Studies 23(7): 2789-2820.

http://dx.doi.org/10.1093/rfs/hhq035

Clayton, M. J.; Reisel, N. 2013. Value creation from asset sales: new evidence from bond and stock markets, Journal of Corporate Finance 22: 1-15.

http://dx.doi.org/10.1016/j.jcorpfin.2013.03.002

Cox, J. C.; Ross, S. A.; Rubinstein, M. 1979. Option pricing: a simplified approach, Journal of Financial Economics 7(3): 229-263. http://dx.doi.org/10.1016/0304-405X(79)90015-1

Dai, T. S.; Wang, C. J.; Lyuu, Y. D. 2013. A multiphase, flexible, and accurate lattice for pricing complex derivatives with multiple market variables, Journal of Futures Markets 33(9): 795-826. http://dx.doi.org/10.1002/fut.21565

Denison, C. A.; Farrell, A. M.; Jackson, K. E. 2012. Managers' incorporation of the value of real options into their long-term investment decisions: an experimental investigation, Contemporary Accounting Research 29(2): 590-620. http://dx.doi.org/10.1111/j.1911-3846.2011.01116.x

Dixit, A. K. 1989. Entry and exit decisions under uncertainty, Journal of Political Economy 97(3): 620-638. http://dx.doi.org/10.1086/261619

Dixit, A. K. 1994. Investment under uncertainty. New Jersey: Princeton University Press.

Fernandes, R.; Gouveia, B.; Pinho, C. 2012. Product mix strategy and manufacturing flexibility, Journal of Manufacturing Systems 31(3): 301-311. http://dx.doi.org/10.1016/j.jmsy.2012.02.001

Fisch, J. H.; Zschoche, M. 2012. The role of operational flexibility in the expansion of international production networks, Strategic Management Journal 33(13): 1540-1556.

http://dx.doi.org/10.1002/smj.1999

Hu, C.; Jiang, W.; Lee, C. F. 2013. Managerial flexibility and the wealth effect of new product introductions, Review of Quantitative Finance and Accounting 41(2): 273-294.

http://dx.doi.org/10.1007/s11156-012-0310-3

Hubbard, R. G. 1994. Investment under uncertainty: keeping one's options open, Journal of Economic Literature 32(4): 1816-1831.

Knight, R. F.; Pretty, D. J. 1996. The impact of catastrophes on shareholder value. Templeton College.

Knight, R. F.; Pretty, D. J. 1998. Value at risk: the effects of catastrophes on share price, Risk Management 45: 39-42.

Lind, R. C. 1990. Reassessing the government's discount rate policy in light of new theory and data in a world economy with a high degree of capital mobility, Journal of Environmental Economics and Management 18(2): S8-S28. http://dx.doi.org/10.1016/0095-0696(90)90035-W

List, J. A.; Haigh, M. S. 2010. Investment under uncertainty: testing the options model with professional traders, The Review of Economics and Statistics 92(4): 974-984.

http://dx.doi.org/10.1162/REST_a_00041

Lund, D. 1993. The lognormal diffusion is hardly an equilibrium price process for exhaustible resources, Journal of Environmental Economics and Management 25(3): 235-241.

http://dx.doi.org/10.1006/jeem.1993.1045

Mandelbrot, B. B. 1963. The variation of certain speculative prices, The Journal of Business 36(4), 394-419. http://dx.doi.org/10.1086/294632

Mandelbrot, B. B. 1997. The variation of certain speculative prices. New York: Springer.

http://dx.doi.org/10.1007/978-1-4757-2763-0_14 
Merton, R. C.; Brennan, M. J.; Schwartz, E. S. 1977. The valuation of american put options The Journal of Finance 32(2): 449-462. http://dx.doi.org/10.1111/j.1540-6261.1977.tb03284.x

Pindyck, R. S. 1991. Irreversibility, uncertainty and investment, Journal of Economic Literature 29(3): 1110-1148.

Pyo, U.; Shin, Y. J.; Thompson, H. E. 2012. Reducing agency conflicts with target debt ratios, Journal of Economics and Finance 3: 1-23. http://dx.doi.org/10.2139/ssrn.2167379

Rubinstein, M. 1976. The valuation of uncertain income streams and the pricing of options, The Bell Journal of Economics 7(2): 407-425. http://dx.doi.org/10.2307/3003264

Sewalk, S.; Dai, Q. 2014. Valuing real options in hospital expansions using vertical phasing, Real Estate Finance 30(4): 156-166.

Sharpe, W. F. 1964. Capital asset prices: a theory of market equilibrium under conditions of risk, The Journal of Finance 19(3): 425-442.

Teversy, A.; Kahneman, D. 1974. Judgment under uncertainty: heuristics and biases, Science 185(4157): 1124-1131. http://dx.doi.org/10.1126/science.185.4157.1124

Tsekrekos, A. E.; Shackleton, M. B.; Wojakowski, R. 2012. Evaluating natural resource investments under different model dynamics: managerial insights, European Financial Management 18(4): 543-575. http://dx.doi.org/10.1111/j.1468-036X.2010.00544.x

Unser, M. 2000. Lower partial moments as measures of perceived risk: an experimental study, Journal of Economic Psychology 21(3): 253-280.

http://dx.doi.org/10.1016/S0167-4870(00)00004-0

Veld, C.; Veld-Merkoulova, Y. V. 2008. The risk perceptions of individual investors, Journal of Economic Psychology 29(2): 226-252. http://dx.doi.org/10.1016/j.joep.2007.07.001

Wenqing ZHANG is Assistant Professor of Operations Management at the Labovitz School of Business and Economics, University of Minnesota, Duluth. He earned his Ph.D. from McGill University. His research interests are in areas that include responsible operations/supply chain management, operations management and marketing interface, game theoretic modeling, quantitative analysis, and optimization models. He has published several papers in these areas in international journals.

Prasad PADMANABHAN is Professor of Finance, Myra Stafford Pryor Chair of Free Enterprise, and Sam Walton Fellow, at the Greehey School of Business, St. Mary's University, San Antonio, TX. $\mathrm{He}$ earned his Ph.D. from McGill University. A prolific researcher, he has published over 30 articles in several prominent professional and academic journals in a variety of areas that include finance, international finance, and international business.

Chia-Hsing HUANG is Professor of Finance and Vice Dean at SolBridge International School of Business, Daejeon, South Korea. He earned his Ph.D. from the University of Pennsylvania. He has taught and worked in the US, Taiwan, and Thailand. He has published extensively in many leading international journals. 